\title{
The Integration of Technology in New Student Orientation Programs
}

\author{
Michael Miller and Patty Viajar
}

New student orientation programs are typically designed around a loosely defined set of expectations that assist in the social and academic transitions to college. An area that has only begun to receive considerable attention in these programs has to do with technology orientation. The current study reports what orientation coordinators perceive to be the most effective strategies for incorporating technology into new student orientation programs. Coordinators agreed most strongly with the notion of emphasizing the importance of technology to new students coupled with providing new students email accounts immediately upon arrival to campus.

Technology use and exposure is pervasive in American society. Rakoff (2001) reported that $75 \%$ of those aged $18-29$ and $45 \%$ of all children have internet access, that $\$ 64$ of middle-income and 38\% of low-income families have internet access, and that over 104 million Americans are on-line. The amount of information stored on-line is substantial, with at least one estimate providing a figure of something equivalent to four billion book volumes that would require 400 million square feet for storage if everything on-line would be printed to a hard-copy (Kittay, 2001). College and university responses have varied substantially, ranging from requiring new students to own a personal computer to non-intrusive policies that simply provide campus computer laboratories. These variations often reflect a campus posture toward the importance of technology.

As technology becomes more prominent in society in general and on campus in specific, there is a need for institutions to examine what the student expectation is, and how this expectation is communicated to students. As Mullendore (1992) argued, new student orientation programs are a time to convey institutional expectations, and subsequently, it would make sense to include something about technology in a transitional program such as new student orientation.

New student orientation programs are rich learning environments where a broad number of expectations and resources are furnished to new students and learning communities that include social and support-network environment construction (Twale, 1989). In many cases there is so much information that orientation programs are multiple-semester in length and include a series of meetings, mentoring, and courses. Little formal exploration has been undertaken in the area of orientation program academic content. Programs typically include a "tips from the faculty" or "essential study skills," but few diagnostic efforts have been directed at program content. The current study was designed to address technology and new student orientation program

Michael Miller, EdD is the Associate Dean of the College of Education at San Jose State University. Patty Viajar, MA is a Lecturer in the Department of Instructional Technology also in the College of Education at San Jose State University. 
content, and to specifically identify how orientation program directors include the integration of technology in their programs.

By identifying how program directors integrate technology into new student orientation programs, baseline data can be reported about the national norm, and begin a conversation about program expectations. Only by beginning this conversation among professional associations, such as the National Orientation Directors Association (NODA), the National Association of Student Personnel Administrators (NASPA), and the American College Personnel Association (ACPA), can student needs, concerns, and development be addressed. Failure to actively seek the conversation and construct meaning for transitional programs has the potential to evolve into environments where pre-existing knowledge levels for new students are mandated without regard to necessary transitions.

\section{Background of the Study}

The incorporation of technology onto college campuses has been taking place for at least the past decade. Part of the rationale for this incorporation is the finding that students learn more material, learn and understand it better, and retain material longer when multi-media are utilized (Perry \& Perry, 1998). Indeed, a technologically capable student body is critical to promoting life-long learning, particularly in areas related to community socialization and the construction of an ability to continue learning once departed from campus. Juke and McCain (1997), however, noted that technology has been slower to be imbedded into the instructional culture of campus because of past experiences with other media. For example, the promise of instructional television has never been as extensive as initially projected.

Different levels of technological competence have been mandated by different state governments and in different institutions. Some universities have begun requiring that new students have personal computers, while others see requiring such hardware as a form of economic discrimination. The State of California mandated that all teacher preparation programs train teachers who are fluent, critical users of technology to demonstrate a relevant education, thus impacting both higher and secondary education (Commission on Teacher Credentialing, 1999).

New student orientation programs have traditionally been designed to fulfill a variety of functions, serving the needs of a broad-spectrum of campus offices in addition to those needs identified by college students. The rationale for program design has been largely tradition-based, but in the late-1980s senior student affairs officers developed and reached consensus on Standards for New Student Orientation Programs. Published by the Council for the Advancement of Standards (1988), these 20 standards provide a foundation for understanding what orientation should include. Identified for inclusion in orientation are such standards as developing positive relationships with other new students, institutional faculty and staff, others from the institutional community, personal definition of attending college, and providing information on registration, student support services, and an awareness of non-classroom opportunities.

Students, however, do not always agree with all of the 20 CAS standards, as 
reported by Nadler and Miller (1997). Of the 20 standards, students entering a case study institution in the fall of 1996, only four of the 20 were agreed to as important and central to orientation. These four were developing positive relationships with other new students, providing appropriate information on personal safety and security, promoting an awareness of non-classroom opportunities, and providing information concerning academic policies, procedures, requirements, and programs. Students had very moderate agreement that new student orientation should teach about the university's mission or explore the student's purpose in attending the university.

Despite what might be considered institutional differences, orientation programs can be powerful tools for ensuring student academic success and for the improvement of student retention. In a case study at a community college (Stephenson, 1997), for example, completion of a first year student success orientation course resulted in both higher cumulative grade point average attainment and a higher retention rate to graduation.

The responsibility of orientation directors and programs to explore or teach about technology use, services, or skills has been relatively unexplored. Despite the pervasiveness of technology on campus, little literature has addressed orientation's responsibility to technology competence. Technology instruction has been a common theme in faculty and staff development and in discussions of general professional development, but there seems to be an assumption that technology competence is to be addressed through formal coursework rather than treated as a fundamental communication or life-skill for undergraduate students. This mixed message has the potential to be counter-productive, implying what is a normal expectation for faculty and staff to receive for free, students must pay tuition to learn.

\section{Research Procedures}

As the current study was exploratory in nature, a researcher-designed survey instrument was constructed. Items for the survey instrument were identified from the literature base and catalogued for presentation to new student orientation program directors and coordinators who were members of the National Orientation Directors Association (NODA).

The 18-item survey was structured so that respondents rated their perceived agreement level on a 1-to-5 Likert-type scale. The scale provided the descriptors that $1=$ Strong Disagreement, that is, the item would not be an effective way to integrate technology into a new student orientation, progressing to $5=$ Strong Agreement that the item would be an effective strategy for incorporating technology. The numeric rating of "3" was used to identify undecided perceptions. The survey was presented to students in an instructional technology program to review for face validity, and appropriate changes were made to reflect a user-friendly survey instrument.

A random sample of 100 orientation professionals was selected from the 2000 NODA Membership Directory using a table of random numbers. The sample was selected from the NODA membership, as the association has historically been the foremost collection of individuals responsible for orientation programming. The sample 
size was based on two factors, including cost and the theoretical argument that variance in sample sizes is not cost-effectively significant in sample sizes over 100 (Alreck \& Settle, 1985).

The survey instrument was mailed to members of the sample in the summer of 2001. One additional mailing was done to non-respondents in an attempt to increase responses. Due to financial restraints, only this second mailing was conducted, and email reminders were sent to non-respondents two weeks after the second mailing was completed.

\section{Findings}

After the second mailing and electronic mail reminder, a total of 67 usable (67\%) responses had been received. Two responses were received that were determined to be invalid, as the respondent provided written comments declining participation in the study. Of the 18 items that the study participants rated, seven were had overall mean scores between 4.07 and 4.66, indicating levels of agreement to strong agreement. Eight items had overall mean ratings between 3.97 and 3.12, indicating neutral perceptions to leaning toward agreement. Three items had overall mean ratings of between 2.70 and 2.45 , indicating levels of disagreement that the strategy would not be an effective strategy to integrate technology into a new student orientation program.

For the seven items that were agreed with, all standard deviations were less than 1.0 , ranging from a low of .54 to a high of .80 . Three of the eight items in the neutral-toagree range had standard deviations of 1.0 or greater, and two of the three in the disagree range had standard deviations of 1.13 or higher. The range of standard deviations reinforces the mean ratings indicating that there is consensus among the items that were agreed with. Also, the range of standard deviations in the disagree category reflects responses that tend to be polarized at both ends of the rating-spectrum, rather than reflecting consensus at the lower-end of the disagreement scale.

As shown in Table 1, the seven items that had mean ratings above 4.0 (agree) were: provide new students with university email accounts immediately when they arrive on campus (mean 4.66; SD .54); emphasize the importance of technological competence (mean 4.32, SD .71); provide computer workstations for pre-registration at orientation (mean 4.28; SD .67); provide on-line demonstrations of how to navigate university services (mean 4.24; SD .70); use virtual tours of campus on line prior to the student's arrival on campus (mean 4.18; SD .80); offer a special session on technology support at the college/university (mean 4.16, SD .78); and provide chat-rooms for new students to ask questions of orientation team leaders (mean 4.07; SD .80).

Also shown in Table 1, three items had an overall mean rating below 3.0, falling in the disagree with the statement range. These items were specific, and included having a presidential address through web-casting (mean 2.70, SD .95), requiring students to own a personal computer (mean 2.58; SD .1.19), and buying athletic tickets only through the use of technology (mean 2.45; SD 1.13). 


\section{Discussion}

Colleges and universities have invested heavily in computing, in terms of management systems, academic computing, and instructional technology. With increases in technological capabilities and user-friendliness and decreases in costs, campuses will in all likelihood continue to make substantial uses of computer technology. The role that divisions of student affairs play in using this technology becomes increasingly important, whether for simply "going-paperless" or for enrollment management, and subsequently, has a dynamic impact on new student orientation. If orientation programs truly are a key mechanism for providing a set of institutional expectations, then how student affairs works with new student orientation to convey technological knowledge and its use is of paramount importance.

The orientation directors in the current study provide a good first look at what types of programming an institution could consider. The overall mean ratings did not have strong thematic clusters, reflecting that orientation directors looked at each item individually, and have an entire spectrum of possible responses to how technology should be used. For example, orientation directors agreed fairly strongly that new students should have university-sponsored email accounts and that computer workstations should be used for pre-registration. At the same time, using the new university sponsored email account for a daily orientation newsletter got mixed reviews, and very neutral perceptions were reported about making a portion of orientation all on-line.

What these ratings do provide is an initial look at what orientation directors are thinking about. A strong next step would be to work with students going through orientation programs and asking those students who are already on-campus about what they think new students need to and should know about computing and technology on campus. The possibilities for including technology in orientation are multi-dimensional, and simply need to be the focus of a serious conversation and inclusion.

An interesting dimension to this dialogue is the question of who is to be included in determining technology inclusion and format. Each campus will have their own resource structure; therefore, an inventory of what each campus has is necessary before starting to include technology in orientation. In this conversation, it may be beneficial to include representatives of the campus information systems group, as their expertise in the framework of the campus connectivity can assist in determining what actually can be done on campus. Not including them could be detrimental to the goals of the inclusion of technology and a non-effective use of resources. If the campus has a technology board that has oversight for the introduction of technology to the campus, their advice and resources could assist in developing the items to be used, as well as determining criteria to ensure quality and consistency.

Another area that could be addressed is the support or training that is needed to use the technology. Having the technology available is only one dimension of the issue, and being able to use the technology in an expert capacity is equally important. There should also be backup and support systems in place to help both the new students transitioning to campus as well as the orientation team leaders. 
Developing orientation programs based on the previous year's orientation activities does not reflect the importance or power of orientation. For new student programs to realize their potential in assisting with the transition to college and in assuring matriculation, orientation directors need to reflect on past experiences as well as explore new possibilities in identifying program content.

\section{References}

Alreck, P. L., \& Settle, R. B. (1985). The survey research handbook. Homewood, IL: Richard D. Irwin.

Commission on Teacher Credentialing. (1999). Final report of the computer education advisory panel. Sacremento, CA: California Commission on Teacher Credentialing and the State of California.

Council for the Advancement of Standards. (1988). Standards and guidelines for new student orientation programs. Washington, DC: Author.

Juke, I., \& McCain, T. (1997). Living on the future edge. Retrieved online through the Thornburg Center at http://www.tcpd.org/tcpd/handouts.html.

Kittay, J. (2001). (Ed.). Overbooked, what if you had to build a place to store the world wide web? University Business, 4(3), 48-49.

Mullendore, R. H. (1992). Student based programming in orientation. In D. P. Nadler (Ed.), Orientation Directors Manual (pp. 43-52). Statesboro, GA: National Orientation Directors Association.

Nadler, D. P., \& Miller, M. T. (1997). Student satisfaction with orientation: A program assessment and cultural stratification. Journal of College Orientation and Transition, 5(1), 7-15.

Perry, T., \& Perry, L. A. (1998). University student's attitudes towards multimedia presentations. British Journal of Educational Technology, 29(4), 375-377.

Rakoff, J. S. (2001). E-boredom? University Business, 4(3), 16.

Stephenson, G. D. (1997). The impact of a student success course on academic achievement and persistence. Unpublished doctoral dissertation, University of Alabama, Tuscaloosa.

Twale, D. J. (1989). Social and academic development in freshman orientation: A time frame. NASPA Journal, 27, 160-167. 
Respondents Mean Ratings of Integration Strategies

$\mathrm{N}=67$

\begin{tabular}{lllll} 
Strategy & Mean & SD & Range & n \\
\hline $\begin{array}{l}\text { Provide new students } \\
\text { with university email }\end{array}$ & 4.66 & .54 & 2 & 65 \\
$\begin{array}{l}\text { accounts immediately } \\
\text { when they arrive } \\
\text { on campus. }\end{array}$ & & & & \\
\end{tabular}

Emphasize the

4.32

.71

3

65

importance of

technological

competence.

Provide computer

4.28

.67

2

65

workstations for

pre-registration at

orientation.

Provide on-line

4.24

.70

3

67

demonstrations of

how to navigate

university services.

Use virtual tours

4.18

.80

67

of campus on line

prior to the student's

arrival on campus.

Offer a special session on

technology support at the

college/university.

Provide chat-rooms for new

students to ask questions of

orientation team leaders.

Require a component of 
Strategy

Provide each new student's

email account a daily

newsletter of orientation

happenings.

Put residence hall move in

regulations on-line.

Provide new students with

technology to experiment with.

Have a person of authority

(president) stress the

importance of technology use.

Have an on-line treasure hunt

to encourage new students

to look at the college's web-site.

Require technology interface

during orientation (such as virtual campus tour, teleconference with the president's office, etc.).

Make a portion of the orientation all on-line (such as a session on study skills).

Have a presidential address through web-casting.

Require new students to have personal computers.

Make athletic ticket purchasing/ lottery available only through technology.
3.79

Mean

SD

Range

$\mathbf{n}$

3.85

.97

4

65

87

3

61

3.54

1.00

65

67

3

4

3.42

.92

4

67

3.24

.94

4

67

3.12

1.05

4

65

2.70

.95

4

67

2.58

1.19

4

64

2.45

1.13

4

65 